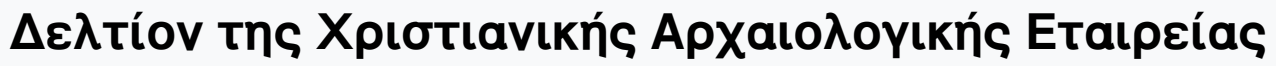

Tóp. 4 (1939)

$\Delta \varepsilon \lambda$ tíov XAE 4 (1936-1938), Пврі́обос Г'

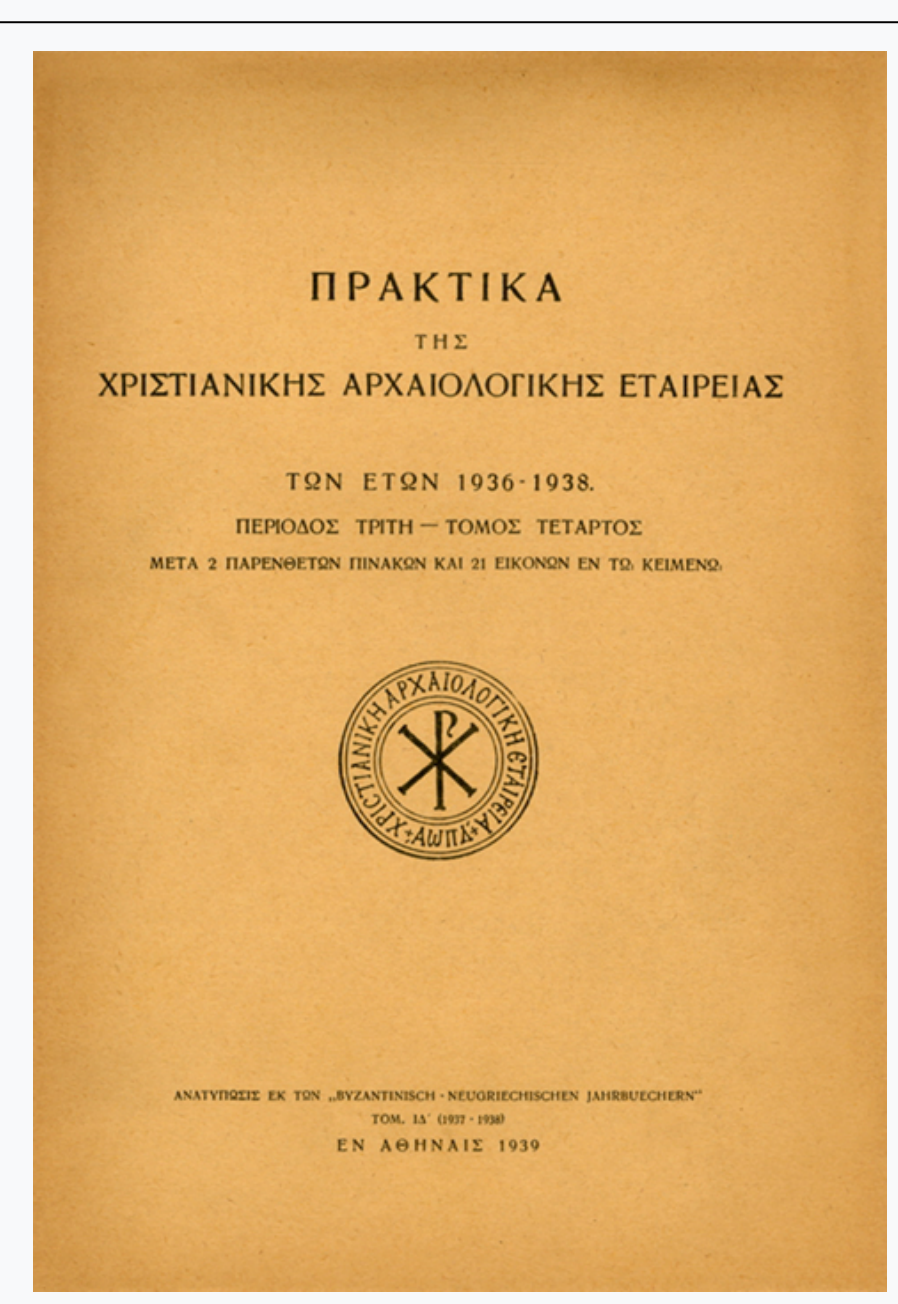

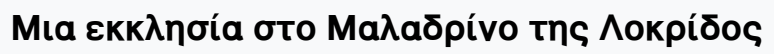

Christos KARUSOS

doi: $\underline{10.12681 / \text { dchae. } 1418}$

\author{
$\triangle 1$ (19)
}

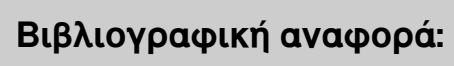

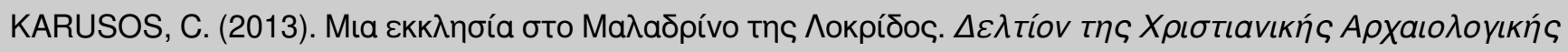
Etalpeía s, 4, 50-52. https://doi.org/10.12681/dchae.1418 


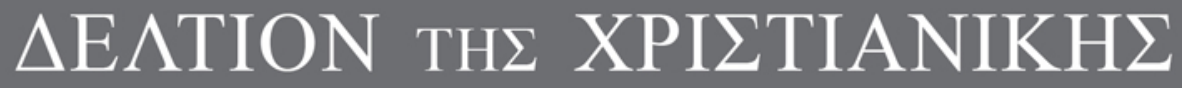 APXAIO $\Lambda$ OГIKH $\Sigma$ ETAIPEIA $\Sigma$}

Eine Kirche bei Maladrino in W. Lokris.

Christos KARUSOS

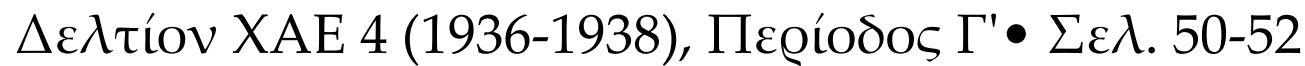
A@HNA 1939 


\section{EINE KIRCHE BEI MALADRINO IN W. LOKRIS}

Von

CHRISTOS KARUSOS.

Zweck der im Mai 1932 ausgeführten kleinen Grabung war die Vorbereitung einer Untersuchung der Ruinen von Physkos, jener bedeutenden Stadt der Ozolischen Lokrer, deren Akropolis- und Stadtmauern noch in ziemlich gutem Erhaltungszustand dastehen. Zunächst wurde die verfallene spätbyzantinische Kirche des Agios Jannis untersucht, die einige Minuten südlich vom Dorf Malandrino und westlich vom Stadthügel liegt, und unter der man die Reste des berühmten Tempels der Athena Ilias vermutet hatte (vgl. zuletzt 'A@xaıo. $\Delta \varepsilon \lambda \tau$. Vl, I920-2I, I50 ff.). Letztere Hypothese wurde jedoch durch die Ausgrabung bisher nicht bestätigt: weder unter der Kirche, wo die Grabung ziemlich tief gegangen ist, noch in ihrer unmittelbaren Umgebung sind antike Mauern zu Tage gekommen (vielleicht muss der Athena-Tempel überhaupt innerhalb der Stadtmauer gesucht werden); das Material, mit dem die Kirche und die sonstigen christlichen Denkmäler an dieser Stelle gebaut sind, ist zwar altgriechischen Gebäuden entnommen, die aber sonstwo liegen.-Der ausgegrabene Teil beträgt in der Länge $6.44 \mathrm{~m}$ und in der Breite $6.32 \mathrm{~m}$ und gehört offenbar zum Atrium der frühchristlichen Kirche. Der Fussboden ist mit farbigen Mosaiken geschmückt; der MittelteiI zeigt stilisierte Epheublätter, die durch Flechtband und einander schneidende 
Kreise umrahmt sind; die Farben sind weiss, blau, rosa und ziegelrot. Der Fussboden trägt ausserdem zwei Mosaikinschriften, von denen die eine stark zerstört und schwer zu lesen ist, die zweite aber folgendermassen lautet:

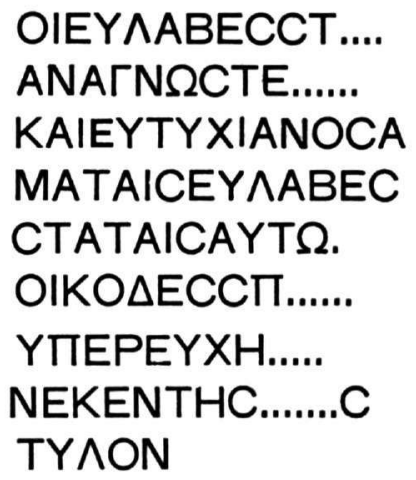

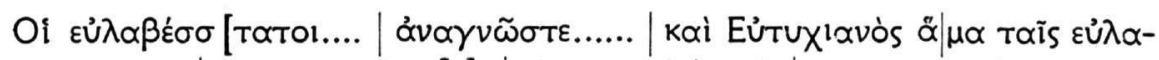

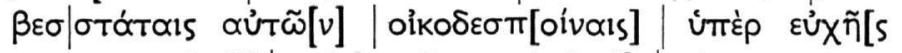

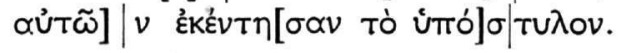

Etwas südlicher von der Agios Jannis-Kirche war von jeher der Teil einer kleinen runden, ebenfalls aus antiken Steinen gebauten Mauer sichtbar, die auf einem ihrer Orthostaten die Inschrift BCH 1898, 354 trägt und von den Archäologen für eine Nische oder Exedra gehalten wurde (vgl. 'A@x. $\Delta \varepsilon \lambda \tau$. a. a. O.). Die Ausgrabung, die die "Nische" in grösserem Umfang freilegte, zeigte jedoch, dass diese nur das Überbleibsel eines runden Wasserbassins ist, das sehr wahrscheinlich auch in frühchristlicher Zeit gebaut wurde. Sein Baumaterial entstammt einem runden altgriechischen Monument und besteht aus niedrigen Platten, die die Reste einer frühhellenistischen Weihinschrift tragen (9 Platten sind erhalten, in der zweiten Verwendung ist ihre ursprünglische Anordnung nicht bewahrt) und aus oben und unten profilierten Orthostaten, die auf der durch die Platten gebildeten Stufe ruhen. Der Boden wurde durch einen aus Kalk und Ziegeln bestehenden Estrich wasserdicht gemacht. Ein Ausflussloch ist noch da. Ausserhalb der Orthostaten und um ihren oberen Teil herum läuft ein schmaler Gang, dessen Fussboden aus 
einfarbigen kleinen Mosaiksteinen besteht. Die wenige Meter entfernt liegende frühchristliche Kirche legt die Vermutung nahe, dass es sich bei der runden Anlage um deren Baptisterium handelt.

Diese sehr unvollständige Notiz soll nur bezwecken, die Aufmerksamkeit der frühchristlichen Archäologen auf ein interessantes Denkmal hinzulenken.

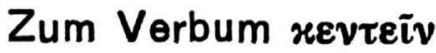

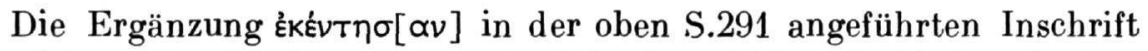

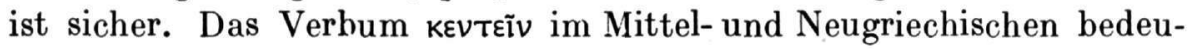
tet sticken, durch Stickereien darstellen, dannim allgemeinen darstellen, insbesonderedurch kleine Mosaikstein e. Eine Inschrift aus Gül Baktsché (bei Smyrna)

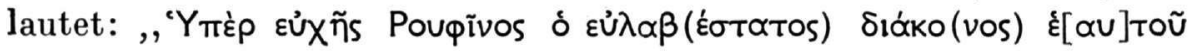

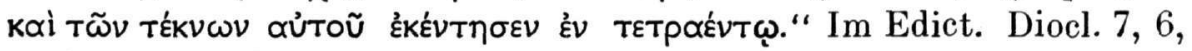

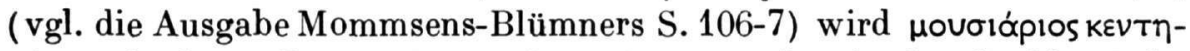

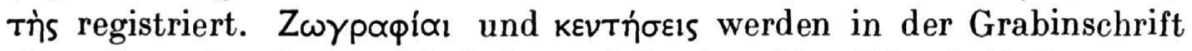
eines alten phrygischen Bischofs, sowie in einer Mosaikinschrift Smyrnas, die vielleicht nicht christlich ist, erwähnt. Vgl. H. Gr égoire in der ,Revue de l'instruction publique en Belgique",Bd. LI(1908)S. 219 ff., LII (1909) S. 166. Recueil des inscript. grecques chrét., Fase. I, S. 26 f., Nr. $90,93$.

Athen - Berlin.

Nikos A. Bees (Béns) 